\title{
Cyclones in the Mediterranean region: present and future climate scenarios derived from a general circulation model (HadAM3P)
}

\author{
Chr. Anagnostopoulou ${ }^{1}$, K. Tolika ${ }^{1}$, H. Flocas ${ }^{2}$, and P. Maheras ${ }^{1}$ \\ ${ }^{1}$ Department of Meteorology and Climatology, School of Geology, Aristotle University of Thessaloniki, Greece \\ ${ }^{2}$ Laboratory of Meteorology, Department of Applied Physics, Faculty of Physics, University of Athens, Greece
}

Received: 25 October 2005 - Revised: 28 November 2005 - Accepted: 6 December 2005 - Published: 13 January 2006

\begin{abstract}
In this paper, an attempt is made to assess and evaluate the skill of the Hadley Center atmospheric General Circulation Model (HadAM3P) in generating successfully the frequency and intensity of severe cyclones $(<1000 \mathrm{hPa})$ in the Mediterranean region. The cyclonic occurrence is studied in three regions of enhanced cyclonic activity: Gulf of Genoa, Southern Italy and Cyprus. It was found that the HadAM3P predicts a future decrease of the frequency of the severe cyclones at the SLP level, but the future cyclones will be more intense (deeper), especially at the $500 \mathrm{hPa}$ level.
\end{abstract}

\section{Introduction}

Mediterranean basin is a well known European region for cyclone formation. The mountain ranges that surround the Mediterranean Sea and the differences between sea and air surface temperature result to a quite complicated temporal and spatial distribution of these cyclones. Hence, cyclonic frequency, intensity as well as the cyclonic tracks have been the subject of several studies (Flocas and Karacostas, 1996; Flocas et al., 2001; Maheras et al., 2002), using both manual and objective methods. The assessment of the future changes of the cyclonic activity in the Mediterranean region considering an enhanced atmosphere with greenhouse gases is very important since these cyclones, and especially the severe ones can be associated with extreme precipitation conditions, severe storms and floods. General circulation models remain nowadays the most appropriate tool for estimations of these future changes.

The main objective of the current study is to a) evaluate the HadAM3P (atmospheric model - Hadley Center) in simulating the main characteristics (frequency and intensity) of the severe cyclones in the Mediterranean region (Gulf of Genoa, southern Italy and Cyprus) and b) analyze the predictions of their future changes according to the model. Besides, a sat-

Correspondence to: $\mathrm{P}$. Maheras

(maheras@geo.auth.gr) isfactory representation of the characteristics of the severe cyclones in the study region by a GCM can render it as a valid source of circulation based predictors that can be used in downscaling techniques.

\section{Data and methodology}

The data employed in the study include time series of daily sea level pressure (SLP) and $500 \mathrm{hPa}$ geopotential heights a) from the NCEP/NCAR Re-analysis project (Kalnay et al., 1996) and b) corresponding simulated datasets of SLP and $500 \mathrm{hPa}$ geopotential heights, as derived by the HadAM3P model. All the datasets consist of grid point values of $2.5^{\circ} \times 2.5^{\circ}$, allowing the study of synoptic scale cyclones. A period of 30 years (1961-1990) is covered for the reanalysis data, consistent with the available period of the control run simulations and 30 years period (2071-2100) for the future based on A2 IPCC scenario.

Surface cyclones with central pressure less than $1000 \mathrm{hPa}$ are considered by applying the objective method (Maheras et al., 2001) based on grid point values, on a daily basis. The analysis focuses on three regions of enhanced cyclonic activity (Maheras et al., 2002): a) Gulf of Genoa, b) southern Italy and c) Cyprus (Fig. 1).

\section{Results}

\subsection{Frequency analysis}

Table 1 depicts the seasonal frequency of severe cyclone episodes detected for each study region using the NCEP, and the HadAM3P data (control run and scenario). In Fig. 2 the calculated frequencies for each of the selected grid points of the three study regions only the winter and autumn, are presented, due to space limitation.

According to the reanalysis data, in the Gulf of Genoa, where both orography and dynamical processes play the most important role for the formation of such cyclones (Maheras et 


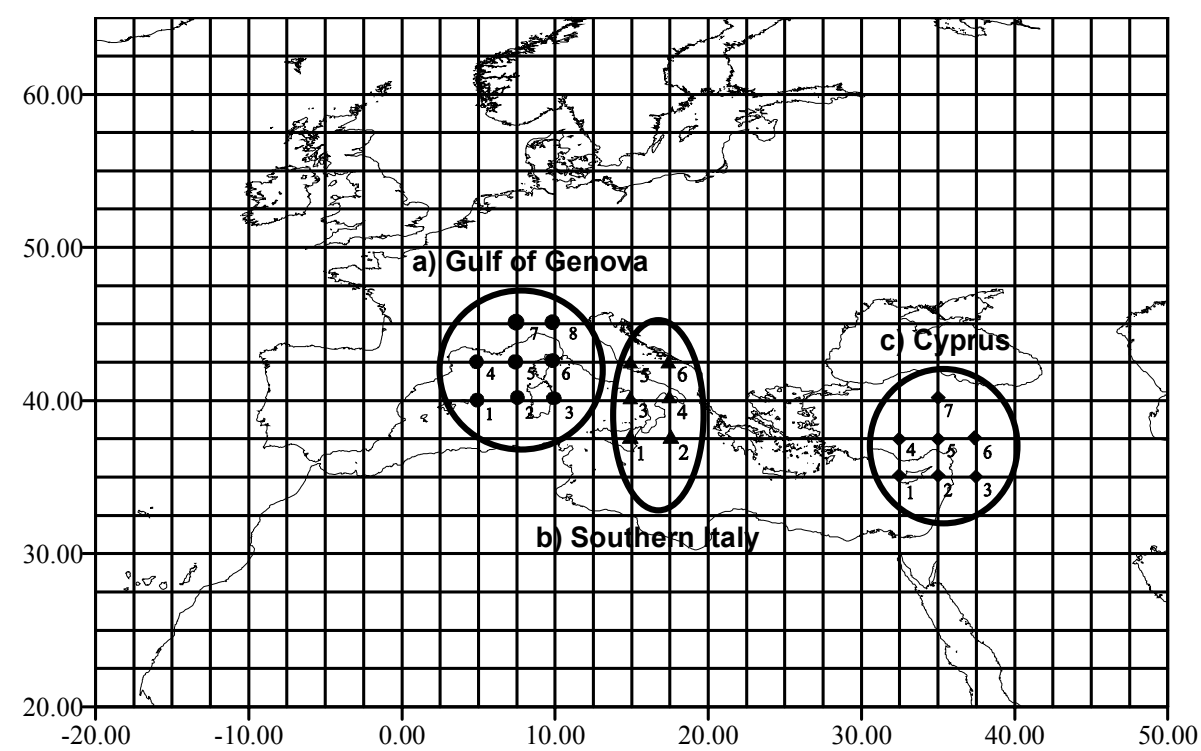

Fig. 1. The selected grid points for the three regions under study.

Table 1. Absolute frequencies of the cyclones for the NCEP (1961-1990), the HadAM3P control run (1961-1990) and for the HadAM3P scenario (2071-2100) for all seasons.

\begin{tabular}{lcccccccccccc}
\hline & Winter & \multicolumn{3}{c}{ Spring } & \multicolumn{3}{c}{ Summer } & \multicolumn{3}{c}{ Autumn } \\
\hline & NCEP & Cont. run & Scen. & NCEP & Cont. run & Scen. & NCEP & Cont. run & Scen. & NCEP & Cont. run & Scen. \\
\hline Genoa & 65 & 20 & 12 & 40 & 38 & 23 & 0 & 1 & 4 & 28 & 15 \\
Italy & 68 & 21 & 12 & 31 & 40 & 40 & 0 & 0 & 3 & 16 & 7 & 5 \\
Cyprus & 19 & 4 & 4 & 51 & 3 & 12 & 23 & 23 & 85 & 3 & 2 & 4 \\
\hline
\end{tabular}

al., 2002), the highest frequencies of the cyclones are found during winter and spring. For these two seasons the model underestimates their frequencies. Especially in winter, the HadAM3P could reproduce only the $30 \%$ of the severe cyclone episodes. The frequencies are also underestimated for the autumn months, and the model generates the $54 \%$ of the corresponding frequency. In summer no cyclones with central pressure under $1000 \mathrm{hPa}$ were found and the GCM was found skillful in reproducing this mode. For the future period (2071-2100), the HadAM3P predicts a decrease of the frequencies of the cyclones in winter, spring and autumn that could yield to a possible shift of cyclone tracks.

Similar results derived from the analysis of the frequencies for southern Italy. Only in spring the HadAM3P control run seems to overestimate the frequencies while predicts a small future increase of the cyclone frequency as compared to the NCEP data. For the Cyprus region, the highest number of severe cyclones was found during spring and summer. In winter and autumn, the frequencies are much lower as compared to the other two regions, due to fact that the depressions reaching the regions have been weakened. The HadAM3P control run underestimates their frequencies, especially during spring. On the contrary, an overestimation of the frequencies is found in summer. It is worth mentioning that, for the summer months the scenario indicates a significant increase of the frequencies of the severe cyclones in the Cyprus area. This could be possibly attributed to a more intense thermal effect due to the increase of temperature (increase of the $\mathrm{CO}_{2}$ concentration) during the future period.

\subsection{Analysis of the biases (control run - NCEP)}

The spatial distribution of the seasonal biases between the control run and the NCEP data anomalies at the SLP level and the $500 \mathrm{hPa}$ is presented in Figs. 3-4. These composite maps were constructed by computing the mean pressure field from the days that the selected grids, in each of the study areas, presented surface pressure below $1000 \mathrm{hPa}$ using NCEP data as well as HadAM3P control run data and then by subtracting the NCEP mean map from the corresponding HadAM3P control run map. Similar composite maps were derived by subtracting the control run mean map from the equivalent HadAM3P scenario map for the estimation of the future changes of the severe cyclones for each study area (Figs. 5-6).

It can be seen that during winter, the atmospheric model is in good correspondence with the NCEP sea level pressure in the case of Genoa cyclones (Fig. 3a1). Respectively, at the $500 \mathrm{hPa}$ level the calculated differences are almost zero 

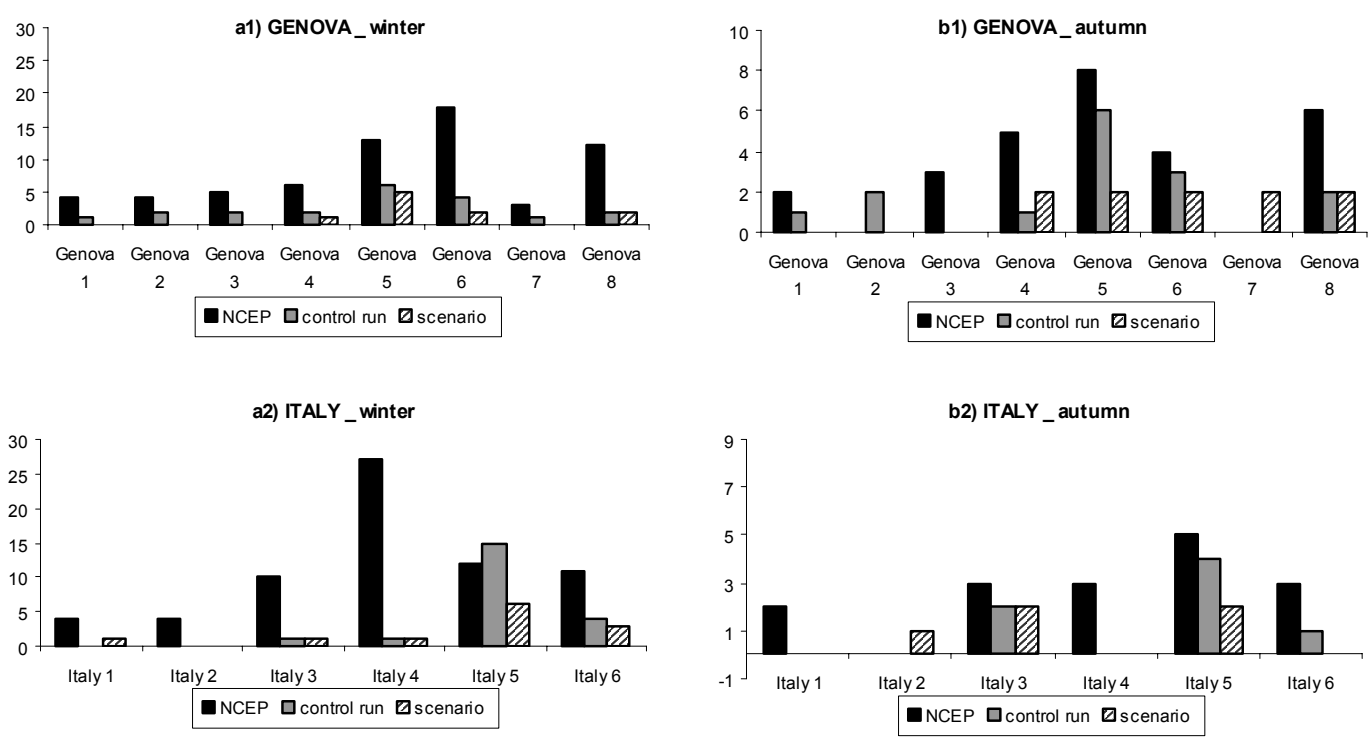

a3) CYPRUS _ winter
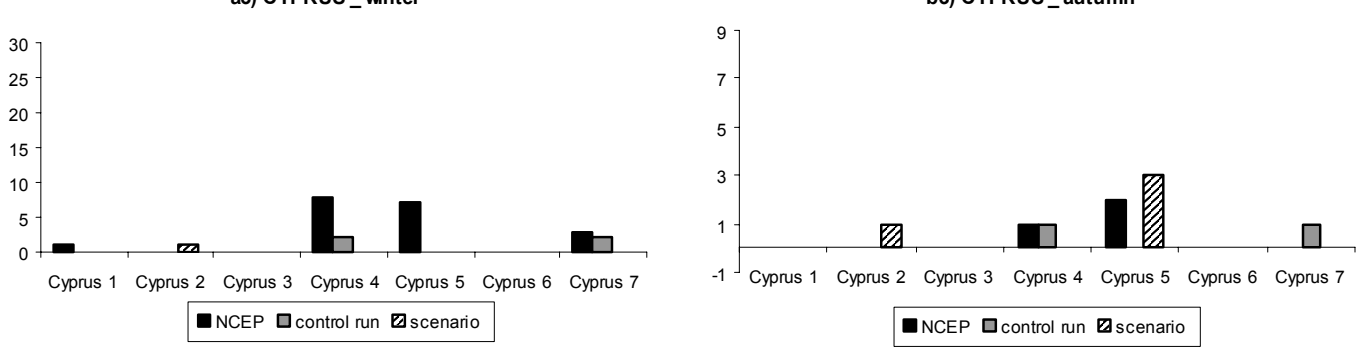

Fig. 2. Seasonal frequencies of the cyclones (central pressure $<1000 \mathrm{hPa}$ ) for the three regions, in the case of winter and autumn. The cyclones were identified at the SLP level.
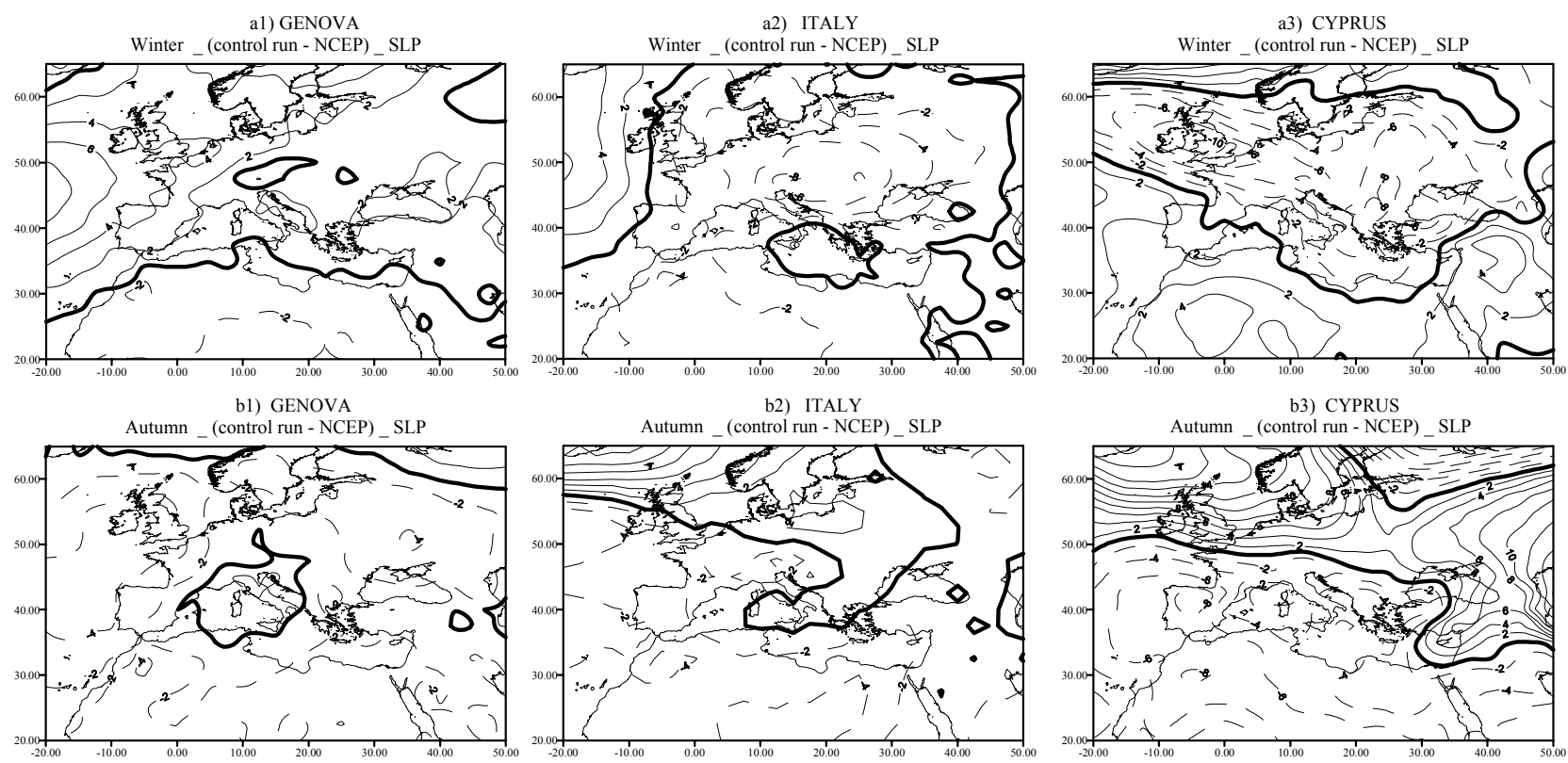

Fig. 3. Seasonal anomaly biases (control run - NCEP) for the three study regions, in the case of winter and autumn for the period 1961-1990 at the SLP level. 

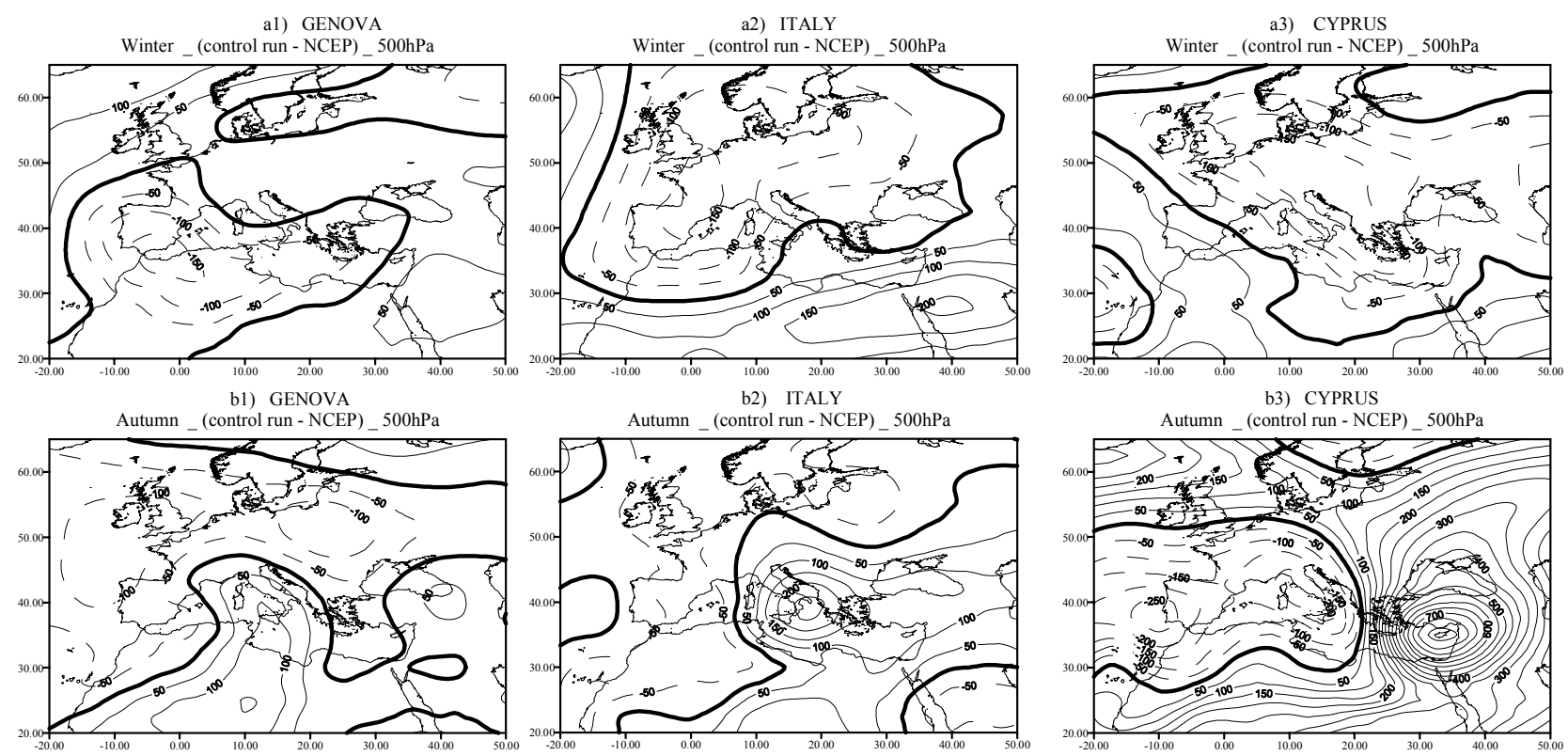

Fig. 4. Seasonal anomaly biases (control run - NCEP) for the three study regions, in the case of winter and autumn for the period 1961-1990 at the $500 \mathrm{hPa}$ level.
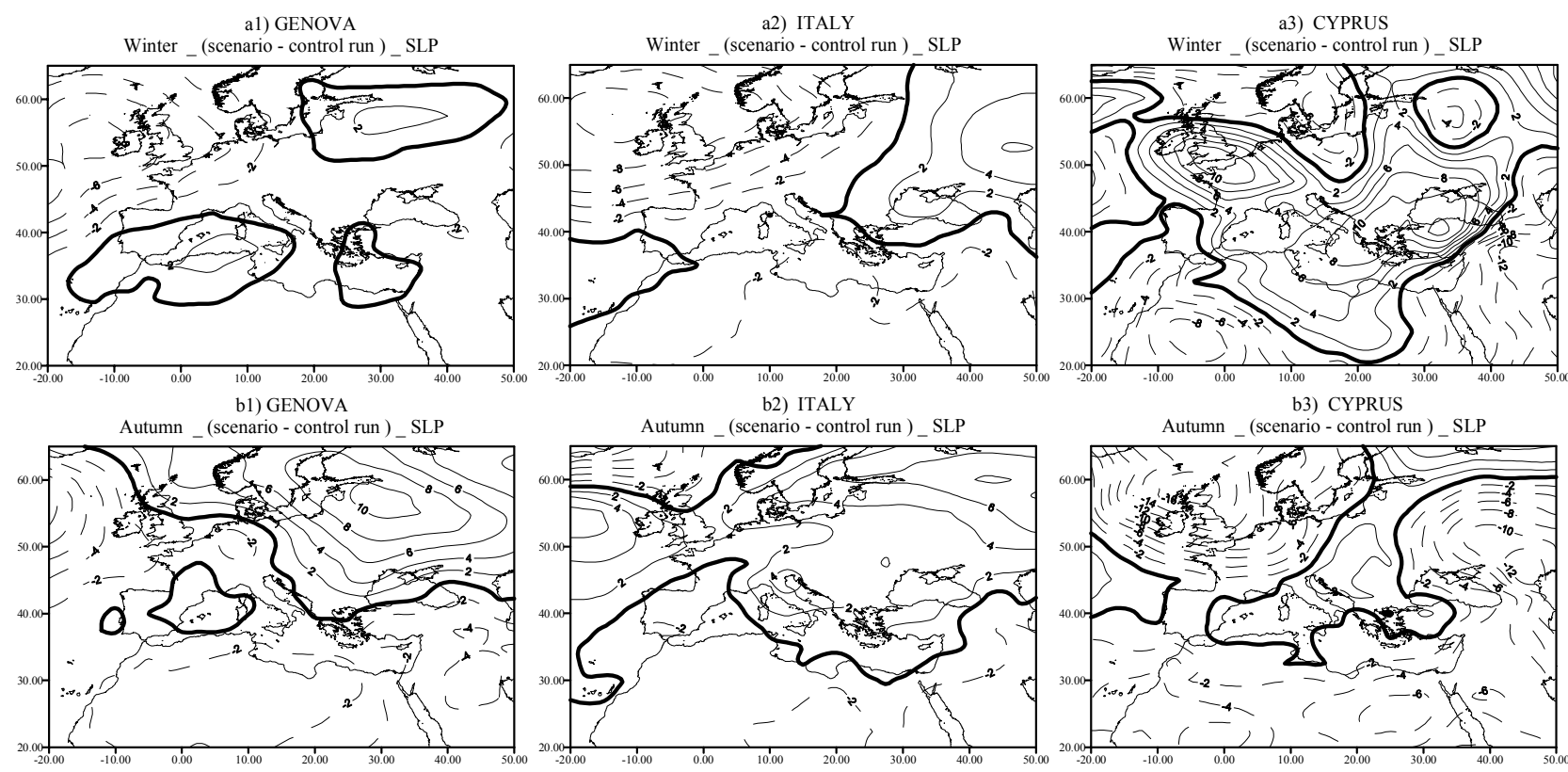

Fig. 5. Seasonal anomaly biases (scenario (2071-2100) - control run (1961-1990)) for the three study regions, in the case of winter and autumn at the SLP level.

above this region, while negative differences cover the largest part of the Mediterranean Sea (Fig. 4a1). The highest absolute values were found in the south of the Iberian Peninsula, indicating that the model underestimates the geopotential values in that area. The analysis of the future changes in Genoa shows that HadAM3P predicts a slight deepening of the severe cyclones during 2071-2100 both at the SLP and at the $500 \mathrm{hPa}$ level. Furthermore, in autumn, the control run data overestimate the geopotential values at the $500 \mathrm{hPa}$ (positive differences), whilst the other parts of the European region are characterized by negative differences (underestimation) for both SLP and $500 \mathrm{hPa}$ levels (Figs. 3,4 a2). Similarly to winter, the HadAM3P scenario estimates a deepening of the severe cyclones, which is more intense at the $500 \mathrm{hPa}$ level (Figs. 5, 6a2). 


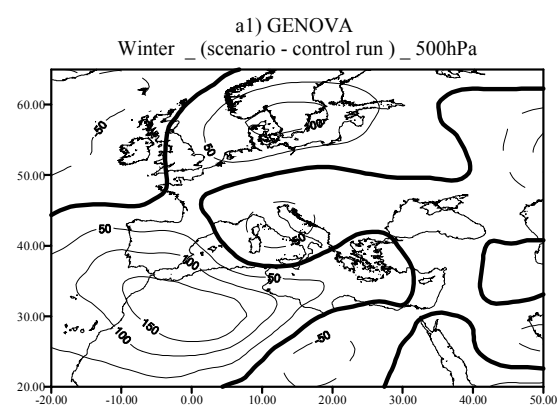

b1) GENOVA

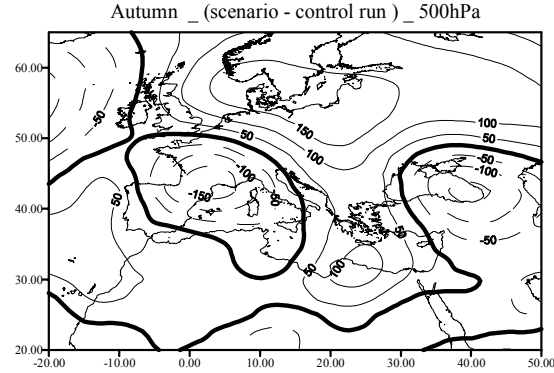

a2) ITALY

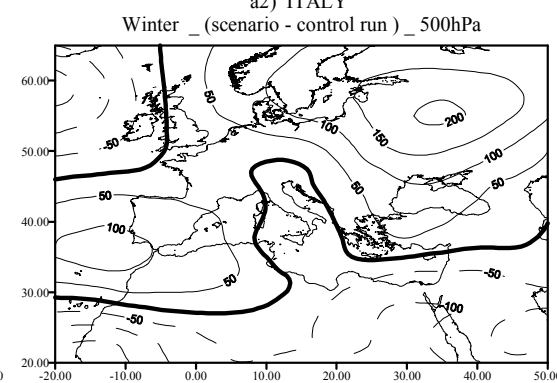

b2) ITALY

Autumn_(scenario - control run )_ $500 \mathrm{hPa}$

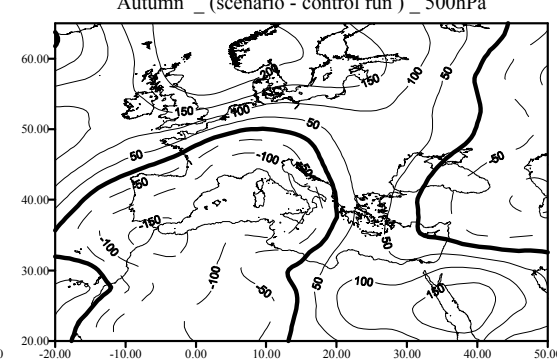

a3) CYPRUS

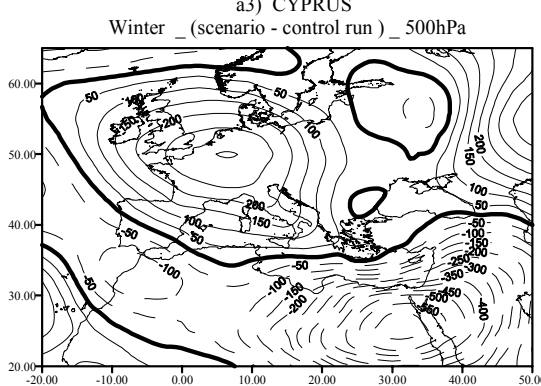

b3) ITALY

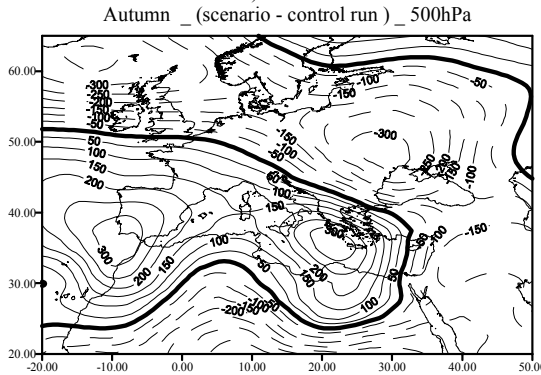

Fig. 6. Seasonal anomaly biases (scenario (2071-2100) - control run (1961-1990)) for the three study regions, in the case of winter and autumn at the $500 \mathrm{hPa}$ level.

The analysis of the composite maps for southern Italy showed that the model underestimates both the winter surface pressure and the $500 \mathrm{hPa}$ geopotential values, not only in this study region but almost in the whole Europe (Figs. 3, 4b1). For the 2071-2100 period, slightly deeper severe cyclones are expected in southern Italy. This deepening is more intense over the British Isles (negative differences), whereas the northeastern Europe is covered by positive differences, as it can be seen at the $500 \mathrm{hPa}$ future map (Figs. 5, 6b1). In autumn positive differences cover the study area, where the model seems to reproduce weaker cyclones (Figs. 3, 4b2). For the future period the atmospheric model estimates a deepening of the severe cyclones, only at the $500 \mathrm{hPa}$ (Figs. 5, 6b2).

The results for the Cyprus region for the 1961-1990 period indicate that only at the $500 \mathrm{hPa}$ level the model underestimates the geopotential, while at the SLP level no significant differences were found (Figs. 3, 4c1). In the future, Cyprus seems to be the transitional area between continental Europe and Middle East, where higher SLP and $500 \mathrm{hPa}$ geopotential values are estimated in the former and lower in the latter (Figs. 5, 6c1). It is worth mentioning that the present spatial distribution of the $500 \mathrm{hPa}$ autumn differences divide the greater European area into two regions. Central and western Europe are characterized by negative differences (underestimation), while eastern Europe and Cyprus are covered by positive differences (overestimation). The differences at the SLP level are not significant (Figs. 3, 4c2). The predicted future changes for autumn denote a slight deepening of the severe cyclones in Cyprus at both levels. However, it should be noted that the surface Cyprus cyclones are characterized by stronger $500 \mathrm{hPa}$ field in the rest of the Mediterranean Sea and Iberian Peninsula and much weaker field in the northeast and the northwest Europe (Figs. 5, 6c2).

For the other two seasons (not shown) the calculated differences were not significant. In spring, only in Cyprus the model reproduces deeper cyclones at the SLP level. Finally, the future estimated changes for these two seasons vary from region to region and no general conclusions can be derived.

\section{Conclusions}

This study is motivated by an interest in evaluating the ability of the atmospheric model (HadAM3P) to generate the frequency and intensity of severe cyclones in the Mediterranean region. The results imply that the HadAM3P control run is not able to simulate the frequency of the severe cyclones in the Mediterranean region, especially in Eastern Mediterranean. The model skill worsens in the cold period when the control run underestimates the frequency of the cyclones in all three study regions. On the contrary, during summer, no cyclones with central pressure under $1000 \mathrm{hPa}$ were found in Genoa and Italy and the model seems to capture quite well this mode.

The scenario results showed that the frequencies of the cyclones will decrease during the future period 2071-2100 in winter, spring and autumn. This decreasing trend could be attributed to the northward extension of the sub-tropical belt during the Global Warming scenarios (Muskulus and Jacob, 2005), resulting to a northward shift of the storm track ( $\mathrm{Li}-$ onello et al., 2002). On the contrary, the increase of the future frequencies of the cyclones in the Cyprus region could be attributed to the more intense thermal effect caused by the temperature increase. Generally, the future results should be 
interpreted carefully because of the HadAM3P low ability, during the control run period, to capture both the frequency and the intensity of the severe cyclones in Mediterranean region.

The analysis of the biases of the SLP pressure and $500 \mathrm{hPa}$ geopotential anomalies during the present period demonstrated that the HadAM3P control run is in good correspondence with the NCEP results with insignificant changes in Genoa and South Italy. However, for Cyprus, the model suggests a reinforcement of the cyclones during winter and mainly spring while for the other two seasons the simulated cyclones are more shallow (higher pressures).

Generally, it could be concluded that the model predicts a decrease in the frequency of the severe cyclones at the SLP level in the future; however, the cyclones will be more intense. It should be noted that the poor skill of the HadAM3P in simulating the Mediterranean severe cyclones in the present seems to limit the reliability of the future predictions. However, our findings are in good agreement with the results of other studies dealing with future changes of atmospheric circulation in the Mediterranean. More specifically, our results are consistent with Carnell and Senior (1988), demonstrating a decrease of the storm number and a tendency towards deeper cyclones in the Northern Hemisphere. Analogous results were found by Lionello et al. (2002) for the Mediterranean region, supporting that this tendency could be attributed to the forced convection as the maritime air masses that are warmer and more humid due to the $\mathrm{CO}_{2}$ concentration increase are blocked by the mountain ridges. However it should be taken into consideration that the coarse spatial analysis of the GCM $\left(2.5^{\circ} \times 2.5^{\circ}\right)$ can not capture all the local parameters affecting the cyclonic formation. The additional use of an RCM data with a finer resolution, as a future work, could lead to more solid conclusions.
Acknowledgements. This work was co-funded by the Ministry of National Education and Religious Affairs (Greece) and EU under the frame of the "PYTHAGORAS" project (EPEAEK II).

Edited by: V. Kotroni and K. Lagouvardos

Reviewed by: anonymous referee

\section{References}

Carnell, R. E. and Senior C. A.: Changes in mid-latitude variability due to increasing greenhouse gases and sulphate aerosols, Clim. Dyn., 14, 369-383, 1998.

Flocas, H. A. and Karacostas, T. S.: Cyclogenesis over the Aegean Sea: Identification and synoptic categories, Appl. Meteor., 3, 5361,1996

Flocas, H. A., Maheras, P., Karacostas, Th., Patrikas, I., and Anagnostopoulou, Chr.: A 40 year climatological study of relative vorticity distribution over the Mediterranean, Int. J. Climatol., 21, 1759-1778, 2001.

Kalnay, E. and co- authors: The NCEP/NCAR 40-year Reanalysis project, Bulletin of the American Meteorological Society, 77, 437-471, 1996.

Lionello, P., Dalan, F., and Elvini, E.: Cyclones in the Mediterranean region: the present and the doubled $\mathrm{CO}_{2}$ climate scenarios, Clim. Res., 22, 147-159, 2002.

Maheras, P., Flocas, H. A., Patrikas, I., and Anagnostopoulou Chr.: A 40 year objective analysis of surface cyclones in the Mediterranean region: Spatial and temporal distribution, Int. J. Climatol., 21, 359-367, 2001.

Maheras, P., Flocas, H. A., Anagnostopoulou, Chr., and Patrikas, I.: On the vertical structure of composite surface cyclones in the Mediterranean region, Theoretical and Applied Climatology, 71, 199-217, 2002.

Muskulus, M. and Jacob, D.: Tracking cyclones in regional model data: the future of the Mediterranean storms, Adv. Geosci., 2, 13-19, 2005. 